\title{
Regarding the issue of self-regulation development in a professional field of the Healthcare system: A doctor's right rather than liability
}

\author{
S. V. Firstov ${ }^{1}$, T. A. Seryak ${ }^{2}$, E. A. Tselishcheva ${ }^{1}$, O. V.Dobrokhotova ${ }^{1}$ \\ ${ }^{1}$ Association of traumatologists and orthopedists of Chelyabinsk region, \\ 46, ul. Tsvillinga, Chelyabinsk, 454091, Russian Federation \\ 2 St. Petersburg State University, \\ 7-9, Universitetskaya nab., St. Petersburg, 199034, Russian Federation
}

For citation: Firstov, Stepan V., Tatyana A. Seryak, Elvira A. Tselishcheva, Olga V. Dobrokhotova. 2020. "Regarding the issue of self-regulation development in a professional field of the Healthcare system: A doctor's right rather than liability". Vestnik of Saint Petersburg University. Law 1: 115-128. https://doi.org/10.21638/spbu14.2020.108

There are several current Healthcare system issues of the Russian Federation in the article that should be considered including the professional liability of doctors, insurance for the liability of medical workers and professional non-commercial organizations' development in health as well as self-regulated organizations. Nowadays, professional liability insurance is voluntary: medical workers have a right to insure any risks of their professional liability enshrined in the federal law on basic principles of public health in the Russian Federation. The development of professional liability insurance in health is hampered by the absence of a federal law on compulsory insurance for medical staff. Adoption of the relevant law would provide a huge impetus to the future of this insurance field. Moreover, one of the duties of medical organizations is insurance in case of harm to the life and (or) health of patients during the administering of medical services according to the federal law. One of the conditions for non-profit organizations to acquire the status of a self-regulated organization is additional property liability for all members involved (activities, services). Self-regulated organization has a right to implement such a method of ensuring property liability for members of the self-regulated organization, such as the creation of a system of personal and (or) collective insurance. Focusing on the above mentioned issues related to the need for legal and social protection of patients and medical staff involved in the process of providing medical care when the life or health of a citizen is harmed, the authors conclude that self-regulation mechanisms are of interest for the Russian Federation Healthcare system. There is also the experience of foreign professional communities discussed in the article.

Keywords: responsibility of medical workers, professional responsibility, insurance of medical workers' professional liability, professional non-commercial organizations, self-regulated organizations, patient, health protection, doctor, medical worker, legal personality, medical service, medical help, Healthcare system.

\section{Introduction}

Currently, the Russian healthcare is in a state of reform and transformation. Despite the fact, that considerable financial resources have been expended by the Ministry of

(C) Санкт-Петербургский государственный университет, 2020 
Health of the Russian Federation to implement various projects, the majority of patients remain displeased with Russian medicine.

Currently reforms, which are under way, do not create sufficient conditions to improve the quality and safety of medical services provided by a practitioner.

Federal law No. 315-FL from December 1, 2007 "About self-regulated organizations" (hereafter - the federal law No. 315-FL) still does not have wide support in the healthcare system (No. 315-FL REW 03.08.2018 the Federal law "About self-regulated organizations" 01.12.2007. Here and after, there are references to legal and regulatory instruments, as well as court practice, provided by the law reference system "ConsultantPlus" (Accessed 27 January, 2019. https://www.consultant.ru). At the same time, self-regulation instruments proposed by the above-mentioned law, including tasks to improve the quality of medical services, modernization of recipient protection mechanisms and health service provider mechanisms are of undoubted interest for the Russian Federation healthcare system. Currently, the topic of self-regulation in healthcare is presented only in some aspects in the scientific community. The number of scientific articles on this matter is extremely limited on the international level as well as in the Russian Federation. When writing this article, we used the following data: regulatory legal acts on the protection of public health, legal acts regulating issues of self-regulation, conferences' proceedings on self-regulation in healthcare which were held on December 2016, June 2017 and November 2018. The purpose of the current study is to identify and justify relevant problems on healthcare selfregulation development in the Russian Federation as an appropriate mechanism to regulate the professional responsibility of doctors. Research methods used include a general scientific means of analysis and synthesis as well as an analysis of regulatory legal acts and method review of the current practice of applying legal acts regulating issues on public health protection and self-regulated organizations.

\section{Basic research}

Self-regulation, like any other complex phenomenon, must be considered from different perspectives to obtain the most complete picture of it.

The concept of self-regulation is directly related to the history of medical associations' development, which dates back to the middle of the $19^{\text {th }}$ century when the first medical associations and medical communities appeared. One of the first to emerge in 1832 was the British Medical Association, which later would have a significant impact on Canada and Australia. Later, in 1847 the American Medical Association was formed. At this period of time, similar examples can be found in many western countries. The establishment of medical associations is a natural step to developing national health systems. So far as healthcare in the middle $19^{\text {th }}$ century was starting to appear, there were no unified standards of medical education and medical services. Moreover, every physician had their own view about their activities and how medical services should be provided.

Unlike economically developed countries, in the USSR and later in Russia there was no national medical association because healthcare system models did not assume an autonomous group of doctors in its structure.

Historically, it turned out to be not an easy task for the medical community in the Russian Federation, due to transformation of the health system and changes in political and economic systems, to save ethical norms and implement the professional law of doctors. 
According to his or her legal position, a doctor in the health system of the USSR and later in Russia had no professional rights and, consequently, no experience of implementing them. More valuable for us are theoretical foundations of self-government and self-regulation that have allowed us to overcome a gap of more than a century (Mikhailov 2019).

In Russian and foreign literature self-regulation is presented as a link between three elements - the government, society and healthcare, implementing its unique role. Examining relationships between healthcare and state, it may be said, that self-regulation provides doctors an opportunity to assume some functions, which had been implemented by the state. Self-regulated organizations can not only set its own norms, rules and standards for members, but also educate them and develop a trajectory of development for the entire sphere.

Thus, doctors have a right to influence the healthcare system and the state takes off part of the responsibility and costs. Considering the interaction between society and health, self-regulation must lead to the improvement of the quality of medical services because self-regulated organizations can introduce higher and new standards of medical services and treatment methods, monitor qualification methods of doctors, and implement their training (Zueva and Khovaev 2014).

According to article 3 of the Federal law No. 315-FL, self-regulated organizations are non-profit organizations based on membership and they unite subjects of entrepreneurial activity on the assumption of production industry unity of goods (works and services) or market of manufactured goods (works and services), or combining subjects of professional activity of a certain type. Also, there are some requirements identified by the Federal law No. 315-FL and in implementing them a non-profit organization may be recognized as self-regulated one, namely:

- association as a part of the self-regulated organization as its members comprise no less than twenty-five subjects of entrepreneurial activity or no less than one hundred subjects of professional activity of a certain type, if the federal laws concerning self-regulated organizations uniting subjects of business or professional activity do not establish another;

- presence of standards and rules of business or professional activity, mandatory for all members of the self-regulated organization;

- providing, by the self-regulated organization, additional property responsibility of each its members before consumers of the made goods (works, services) and other persons according to article 13 of the Federal law No. 315-FL.

Meanwhile, the Federal law from 21.11.2011 No. 323-FL on the basics of public health protection in the Russian Federation (hereinafter - the Federal law No. 323-FL) provides a different model of medical workers' self-organization, different from self-regulation, provided by the Federal law No. 315-FL. According to article 76 of the Federal law No. 323-FL, in order to implement and protect the rights of medical and pharmaceutical staff, to develop medical and pharmaceutical activities, to promote scientific research and to find solutions for other issues related to the professional activities of medical and pharmaceutical workers, these above mentioned workers have the right to voluntarily create professional non-commercial organizations, which can be formed in accordance with following criteria:

- to be a medical or a pharmaceutical worker; 
- to be in profession (a doctor, a physician, a nurse (medical assistant), a pharmacist);

- to belong to one medical specialty (the Federal law "About the basis of public health protection in the Russian Federation" form 21.11.2011 No. 323-FL REW.25.12.2018).

It can be easily noted that article 76 of the Federal law No. 323-FL regulates activity of professional non-profit organizations created by medical and pharmaceutical workers. Professional non-profit organizations of medical workers, considering its features, coincide with the professional unions.

Organizations are excluded from the range of possible actors. It means that medical organizations cannot create the structures listed in article 76 of the Federal law No. 323FL. They can only "push" their employees to create such an organization. It turns out that Russian legislation provides two parallel models:

- model of self-regulation, considering the Federal law No. 315-FL. First of all, it includes combined entities of entrepreneurial activity;

- model of creating professional organizations uniting medical workers as autonomous subjects of law, and also falling under regulations of the Federal law No. 315-FL in the presence of the signs defined by the specified federal law (Romanovskaya 2016, 3).

In the legislation some criteria appear for the first time for doctors' associations, such as: personal membership of doctors and a union of no less than $25 \%$ of the total number of doctors in the territory of the Russian Federation, and they are members of professional organization, and only in accordance with these conditions this organization acquires certain power.

In addition, as section 5 of article 76 of the Federal law No. 323-FL notes, there are some terms to be incorporated that provide the possibility to transfer to medical professional non-commercial organizations, to their associations (unions), which meet the specific criteria defined by the Russian Federation government decree from 17.03.2018 No. 292 "About the approval of criteria and under the condition of compliance with them, medical professional non-commercial organizations and its associations (unions) may be given implementation of certain functions in the field of protecting the health of citizens in the Russian Federation".

Only those medical non-profit organizations and their associations (unions), which meet the criteria defined by the state of the Russian Federation, that implement certain functions in the field of health protection can be transferred.

Such medical professional non-profit organizations may participate in:

- development of norms and rules in the sphere of health protection;

- solving issues related to the violation of these rules and regulations;

- development of procedures for the provision of medical care services and standards of medical care, training programs and advanced training for medical and pharmaceutical workers;

- certification of medical and pharmaceutical workers for their qualification categories;

- accreditation of specialists;

- sign agreements on tariffs for medical services in the system of compulsory medical insurance and in the activities of compulsory medical insurance funds; 
— development of territorial programs for the state guarantee of free medical services for citizens;

- establishment of accreditation committees and accreditation of specialists;

- work of the commissions on an assessment of consequences of decision-making on resolving medical organization's issues, subordinate to the executive body of the Russian Federation or local government, the termination of activity within a seperate division.

Also, medical professional non-profit organizations develop and approve clinical recommendations (treatment protocols) on the provision of medical care issues including the results of clinical tests.

According to the specified resolution of the government of the Russian Federation, medical professional non-profit organizations, their associations (unions) that implement separate functions in the sphere of health protection, shall simultaneously meet the following criteria:

- unite in the structure more than $50 \%$ of medical professional non-profit organizations, according to part 3, article 76 of the Federal law No. 323-FL. This implies that it is based on the personal membership of doctors and unites no less than $25 \%$ of total number of doctors in the territory of the subject of the Russian Federation;

- implement its activity within no less than 3 years with the goals outlined in part 1 , article 76 of the Federal law No. 323-FL, namely: in order to implement and protect the rights of medical and pharmaceutical workers, develop medical and pharmaceutical activities and promote scientific research.

The decision on compliance of medical professional non-profit organizations, their associations (unions) with criteria, approved by the Ministry of Health of the Russian Federation by order of the Ministry of Health of the Russian Federation from 06.07.2018 No. 421 on the statement of the acceptance by the Ministry of Health of the Russian Federation regarding the decision on compliance with medical professional nonprofit organizations, their associations (unions) to the criteria approved by the order of the government of the Russian Federation from 17.03.2018 No. 292 on the approval of criteria provided compliance with which medical professional non-profit organizations, their associations (unions) implement certain functions in the sphere of public health protection in the Russian Federation.

So far, the decision of the Ministry of Health of the Russian Federation on compliance of medical professional non-profit organizations with the criteria approved by decree of government of the Russian Federation dated form 17.03.2018 No. 292, and its allocation of individual functions in the field of public health protection has not been adopted by any organization.

Federal law No. 323-FL establishes a list of the rights for professional organizations of doctors, which can be divided into two groups.

The first group includes the right to participate in law-making activities and to assist state authorities in the performance of basic managerial functions. The second group of powers of professional non-profit organizations of medical workers is associated with the participation of professional organizations in the training and certification of medical workers. 
Thus, the government is trying to transfer burdensome functions and not include professional medical organizations in the circle of participants in public administration. The functions that would allow the professional community to organize itself on the basis of the development of internal decisions and control over their execution have not yet been transferred. We are talking about making binding decisions for doctors, about monitoring their professional activities, and about applying measures of responsibility for violation of professional rules and standards.

Currently, in the territory of the Russian Federation there are many medical workers' associations formed on various grounds including those that do not correspond to section 1 of article 76 of the Federal law No. 323-FL.

According to the concept of medical workers' professional activity system introduction, which can be found on the union of the medical community "National medical Chamber" of the Russian Federation website:

- some medical associations, for example, such as scientific societies of one specialty implement its activity without a legal entity registration;

- in 33 lands of the Russian Federation medical professional non-commercial organizations, corresponding to section 3 article 76 of the Federal law No. 323FL, and specifically medical professional non-commercial organizations based on doctors' personal membership comprise not less than 25 per cent of the total number of doctors rendering services in the territory of one of the lands of the Russian Federation;

- individual medical professional non-commercial organizations created by medical workers implement their activity on medical workers' insurance in cases of risk to human life (health) during the rendering of medical care,, participate in the consideration of complaints (claims) of patients and in pre-judicial settlement of disputes concerning the quality of the rendered medical care, consider questions on medical ethics and deontology, hold professional skills competitions of medical workers and publicize the work of medical staff in mass media. This all helps to increase the prestige of medical professions and actively contributes to improve the legislative system in the field of health protection and projects of regulatory legal acts' development dealing with professional medical activities.

There are also organizations uniting doctors (medical workers) at the federal level from many lands of the Russian Federation, such as the Russian Medical Association, Russian Medical Community, Community of doctors in Russia, Union of Medical Community "National Medical Chamber" and All-Russian organizations of doctors of one specialty (The Concept of self-regulated professional activity of medical workers' system introduction in the Russian Federation. Accessed January 27, 2019. http://www.nacmedpalata.ru/?action=show\&id=17695).

Currently, professional non-commercial organizations formed in healthcare often unite medical organizations, doctors and other highly educated specialists who are involved in healthcare as well as people with specialized secondary education.

In April 2010 the National Medical Chamber was formed and declared its main aim as the creation of a union for all members of the medical community in Russia, based on the principles of self-regulation, to modernize the system of healthcare for the population of Russia. However, the large-scale policy of the National Medical Chamber, including the 
development concept on self-regulation in healthcare, has yet to produce any result on the topic of self-regulation development.

Since 2014 there has been a very broad discussion of issues related to self-regulation in healthcare.

In December 2016 at the IV International Conference "Practical self-regulation" held by the Chamber of Commerce and Industry of the Russian Federation, we presented a report on the topic of the establishment of a self-regulated system in the sphere of healthcare. For the first time we demonstrated an analysis of the existing situation in the industry. Considering the analysis there is a need to separate and create system of voluntary self-regulation for entities of professional activity with the purpose of uniting doctors of one specialty and subjects of entrepreneurial activity with purpose to join medical organizations to solve common tasks aimed at preserving the health and life of citizens.

Any time a physician sees a patient or provides a treatment, he or she enters into a complex web of interlocking systems of public and private professional regulation. These systems delineate the scope of work and restrict who can do what tasks, regulate conduct, and set entry qualifications and ongoing educational standards for physicians. Systems define behavior and set qualification requirements as well as current educational standards for physicians. Because of the ubiquitous nature of systems of professional regulation and their role in defining and enforcing standards of professional conduct, it is important for young medical professionals to understand how they work and the challenges they pose. Moreover, self-regulation is a key component in medicine, and during their careers many physicians may be involved in setting, implementing, and possibly enforcing professional standards. During the entire period of professional activity, many doctors are involved in establishment, implementation and observance of professional standards (White 2015).

In general, for health it is important to know, that doctors are responsible for their activity.

Professional legal personality implies that doctors are in legal relations concerning the provision of medical care services. Consequently, doctors have the following special legal features:

- professional legal capacity;

- professional capacity;

- professional delictual capacity.

Professional legal capacity of the doctor is his ability to have the rights and bear the duties recognized by the current law.

The professional capacity of a doctor is his or her ability to acquire and exercise rights and responsibilities through legal acts.

Professional delictual capacity of a doctor is his ability to take responsibility for the offense.

The first feature of a doctor's legal status ensures his or her individualization as a subject of medical care. Professional legal capacity is closely related to the categories of freedom and responsibility of doctors.

In the aspect of professional legal capacity and capacity of a doctor, it is important to underline that according to article 100 of the federal law "About the basis of health protection of citizens in the Russian Federation," entities with a specialized secondary or higher level medical education in accordance with federal state educational standards and with 
a specialist's certificate, have a right to implement medical activity in the Russian Federation.

Consequently, the professional legal capacity of a doctor is obtained after receiving a medical education confirmed by a diploma or a special title as well as a specialist's certificate or taking an oath. The oath is defined in article 71 of the Federal law No. 323-FL. By taking the oath, a person does his or her own medical duty and is responsible to use his or her knowledge and skills to prevent and treat diseases, to always be ready to provide medical services that adhere to the standards and rules of professional conduct. In particular, the doctor is obliged to comply with the requirements under article 73 of the Federal law No. 323-FL. The specified article prescribes that medical workers are obliged to carry out their activity according to the legislation of the Russian Federation and are guided by the principles of medical ethics and deontology, including medical care services according to the qualification, job descriptions, office and job responsibilities.

Thus, professional responsibility of doctor is one of the forms of social responsibility provided by the internal desire of the doctor to comply with the rules of professional conduct (positive responsibility of the doctor) and norms of legal enforcement of classical types of legal responsibility (negative responsibility of the doctor).

In order to practice medicine in the USA, a physician must be licensed in a certain state. State practice laws set standards for entry and regulate conduct. The primary mechanisms for assuring the competences of those who enter the profession consist of testing and requirements of a minimum level of education and training (White 2015).

For many reasons, nowadays there is negative attitude towards doctors in society. Public opinion demands put doctors in a strict framework of professional standards and regulate the provision of procedures for medical care services, and if the doctor does not follow them, he or she may be held legally liable. But at the same time, as experience in the USA demonstrates, the fight against defects in the provision of medical care services by tightening the civil and criminal liability of doctors does not bring the desired results. It is known from the theory of criminal law that the toughening of punishment does not always lead to the desired result.

It is obvious, that the use of negative responsibility towards health workers has a detrimental effect on healthcare activity and, ultimately, has a negative impact on the basic constitutional values of human life and health. It is always preferable to learn from the mistakes of foreign jurisdictions than one's own. Therefore the USA experience is a very valuable lesson for our legal system (Goriyanov 2019).

A practicing physician has his own professional point of view along with a patient isolated from professional community. This situation today has reached its climax. The risk of making a decision solely without any doubt may lead to frequent medical errors.

The current legislation of the Russian Federation does not have a clear definition of such concepts as "medical error" or "medical negligence," which imply different measures of responsibility.

Medical error is not a deliberate action, which can be caused by both objective and subjective reasons. Mistakes made in medicine are actively discussed in the press and attract the attention of not only medical specialists, but also people far removed from this profession. Without a doubt medical error must be discussed within the medical community to decide whether it was possible to prevent it or not. It also includes follow-up activities to eliminate the possibility of errors. 
In our opinion, issues related to physicians must be regulated by a professional community that unites all doctors. This community unites doctors of one specialty of a certain type in accordance with article 76 of the Federal law No. 323-FL, Federal law No. 315-FL.

Federal law No. 323-FL does not include the terms "self-regulation" and "self-regulated organization" in relation to the status of professional non-profit organizations of medical workers.

Associations of doctors according to the principle of their main specialty, regardless of the medical organization they are employed in (private, municipal or state), will lead to the emergence of a competent expert community, increase the level of doctors' responsibility, and will help to restore the prestige of the doctors and the profession over time.

Additionally, the specified organization can include a number of specialists of one specialty as well as one entity of the Russian Federation, and several entities of the Russian Federation, in total 100 entities and even more.

Moreover, self-regulated system mechanisms provided by Federal law No. 315-FL, do not consider absolute autonomy of professional communities for the following reasons:

- self-regulated organizations develop their own standards and rules, but they must comply with federal standards and rules.

- self-regulated organizations form their own internal protection of professional interests system, but this very system must fully comply with supervisory bodies' requirements.

- self-regulated organizations improve the protection system for patients' interests, but the patient still has all rights to protect his or her own interests in other authorities provided by law, and self-regulatory organizations cannot ignore it.

The main goal for self-regulation development is to improve the quality of provided services. This goal complies with the goal of a professional community and cannot be achieved in complete isolation and in the absence of any contact with state and non-state bodies and organizations (Piven and Kitsul 2011, 25).

One of the mandatory requirements of self-regulation is to ensure property liability for self-regulated organization members in ways established in article 13 of the Federal law No. 315-FL, including the creation of a system of personal and (or) collective insurance or the formation of a compensation fund.

Insurance for the risk of your professional liability is the right of medical workers, provided by article 72 of Federal law No. 323-FL, but none of the doctors implement this right and do not enter into a professional liability insurance contract.

Doctors' professional responsibility insurance providers are medical organizations of any organizational and legal form, as well as individuals (medical workers), who have a license for certain activities in the provision of medical services.

Under the contract of professional liability, an insured event is the fact of hazard, caused due to the following reasons:

1) provision of medical services (assistance) of inadequate quality:

- non-performance, untimely performance or poor-quality performance of diagnostic, medical, preventive and rehabilitative procedures which are necessary for the patient;

- unreasonable (without sufficient indications or in the presence of contraindications) diagnostic, therapeutic, preventive and rehabilitative measures that lead to a 
diagnostic error, choice of erroneous treatment tactics, deterioration of the patient's condition, complication of the disease or lengthening of treatment;

2) violations in the work of medical organizations that damage the health of patients (clients), that caused illnesses (injuries, burns) and complications arising due to the fault of medical workers during a patience's stay in a medical institution, and if additional medical services are required;

3) premature (from a clinical point of view) discontinuation of treatment leads to a deterioration of the patient's condition, development of complications, disease aggravation (except documented cases of discontinuation of treatment on the initiative of the patient or his or her relatives) (Zgonnikov and Pushkareva 2015, 16).

According to article 13 of the Federal law No. 315-FL self-regulated organization is also responsible for the obligations of its members arising as a result of a hazard due to deficiencies, made by a member of the self-regulated organization of goods (activities, services).

As section 3 of article 13 of the Federal law No. 315-FL establishes, an application is a way to ensure that members of a self-regulated organization are responsible for goods (activities, services) and other people of the system of personal and (or) collective insurance. The minimum amount of the insurance for each member, considering the liability insurance contract, cannot be less than thirty thousand rubles a year.

Occurrence of an insured event may be the result of negligence, error, omission, misconduct, abuse and crime. Insured events that occurred due to the last three reasons are usually not covered under the insurance policy. However, in article 963 of the Civil code of the Russian Federation, it is noted, that the insurer is not exempted from payment of insurance indemnity under the contract of insurance of civil liability for causing harm to life and health, only if harm is caused due to the fault of the responsible person. The peculiarity of the implementation of obligatory insurance under the contract of professional liability insurance of medical workers is that the insurer is obliged to pay insurance compensation even when the damage is caused by the insurer or insured person intentionally or grossly negligently (Zgonnikov and Pushkareva 2015, 16).

Among the factors hindering the development of civil liability insurance in the healthcare system, there is the absence of a federal law on compulsory insurance of civil liability for medical workers. The introduction of an appropriate law would be an excellent basis for the development of this type of insurance, because, at least, not many leaders of medical organizations and private practitioners understand the importance of such insurance and often do not even think about the losses that could threaten them. There is no doubt that the adoption of the relevant law will facilitate the development of this insurance sphere (Kapranova 2009).

In connection with this, the rules on professional liability insurance as well as the method of property liability stipulated by Federal law No. 315-FL, and the right of a medical worker to be insured to avoid a risk of his or her professional liability, are interrelated and complementary.

The tools of self-regulation proposed by Federal law No. 315-FL, taking into account the tasks to improve the quality of medical care, modernize mechanisms for recipients' protection and producers of medical services are in undoubted interest to the Russian Federation healthcare system. 
Moreover, if we look at the international experience, the ethical documents of the World Medical Association (in particular, the Madrid Declaration on professional autonomy and self-regulation, October 1987) link professional autonomy of doctors with self-regulation. However, professional autonomy is defined as "doctors are free to exercise their professional judgment in the care and treatment of their patients." The consequence of the right to professional autonomy is the need for self-regulation of the medical profession on a permanent basis: "In addition to any other source of regulation, that may be applied to individual physicians, the medical profession itself must be responsible for regulating the professional conduct and actions of physicians." But in this case, we are referring to self-regulation of professional activity, regardless of the form of its implementation (Romanovskaya 2016, 3).

The idea of voluntary professional self-regulation of doctors within one specialty has already found followers. Today, there are several associations to be registered that already work in the territory of the Russian Federation such as the Association of traumatologists and orthopedists of the Chelyabinsk region, the self-regulated organization professional medical association of high standards in advanced phlebology care "National collegium of phlebologists," which unites experts from all of Russia, as well as the self-regulated organization of MRI-diagnostic specialists. Two of three professional non-commercial organizations, which are included in the self-regulated organization database have a legal address in Chelyabinsk.

These and the other issues were discussed at the second conference of Self-Regulated System development in health on the topic of "SRO of doctors: reality and prospects," held 29 November 2018. The second conference "Self-Regulated system development in healthcare. SRO of doctors: reality and prospects" was organized jointly with the council of professional and entrepreneurial activities of self-regulation with the support of association of Russian diplomats at the chamber of commerce and industry.

At this Conference, reports on the professional activity of self-regulation in health were heard and discussed. At the same time, participants of the discussions for the first time became acquainted with similar foreign experience. With the support from the Association of Russian Diplomats, the event gained an international status. Leaders of professional medical associations from the USA, Bulgaria and Israel presented their reports on the history of their foundation, structure of medical associations and type of relationships among associations, governments and general public.

For example, the Israel medical association represents the interests of all doctors in Israel. The main task for the medical association is to take care of the health system and promote the interests of doctors in all spheres of their activity, which they encounter on a daily basis. The Association deals with a wide range of issues, namely licensing, specialization of doctors, resolution of professional issues, etc.

It should be noted, that a very important aspect of the association's activity is ethics. There is a special department in the Israel Medical Association which deals with issues arising in the process of professional medical activities, in particular, complaints against doctors in terms of ethics, problematic issues arising in the framework of the relationships between doctor and patient, as well as the relationships between doctor and employer. The Israel Medical Association takes the position that the majority of all conflicts at work should be considered on the basis of the association. In general, doctors are provided with a significant protection of their activity, because professional activity of every doctor is 
insured. This medical insurance covers all possible legal claims up to $\$ 3$ million presented to a doctor as part of his or her professional activity. In practice, there are no situations when the amount of insurance compensation within doctors' liability insurance does not cover the compensation claimed in court. Thus, insurance provided by the association provides a doctor with a very high level of his or her material interests.

The American Medical Association (hereafter - AMA) is the main national medical association in the USA. There are more than 170 national medical specialties, state and district medical associations included. AMA represents more than 1 million doctors in the USA. Each state has its own medical association created on the basis of the AMA. Every medical association, as an AMA representative, is a constituent member and an independent body that participates in the legislative process. AMA performs the following functions: promoting medicine as a science and practice, improving health care, motivating doctors and patients to solve health problems, lobbying for bills aimed to improve healthcare. In the USA, the American Medical Association is responsible for cleanliness in the ranks of the medical corps. At the same time, the AMA does not consider and does not determine the capacity of a doctor or admission to the profession. AMA does not regulate activity of a doctor including licensing and discipline. These are functions of medical state committees or territories that are parts of the state government or territory. AMA does not cooperate with the investigative authorities, if there is no such order from the court.

Also, there is national medical association in Bulgaria. As part of its activity, Bulgarian Medical Association (hereafter - BMA) has its own register including 34, 000 doctors. The structure of BMA includes regional collegiums in all regional cities of Bulgaria. The main activity of the BMA consists of the following areas: legislative activity, protection of financial and professional interests of doctors, development of rules for good medical practice, control of compliance with the code of ethics by doctors, legal assistance to doctors and their protection. Moreover, BMA organizes and controls the qualification of doctors and their trainings in order to improve the quality of medical practice.

We share the view of Dr. Richard Cruess, professor of surgery at McGill University's Center of medical education in Montreal, Quebec, who says: "However a country regulates its medical profession, it will remain a tough and complex job, and will always require the involvement, in some form, of physicians. Medicine will remain a difficult field to regulate no matter who is doing it, but it will have to rely on expert opinion" (Collier 2015).

\section{Conclusions}

By creating professional non-profit organizations that unite subjects of a certain type of professional activity and have the status of self-regulated organizations, doctors can develop and approve standards and rules of professional activity, monitor their observance, apply disciplinary measures for violation of standards and rules soundly and on a professional level.

The existence of rights in the professional community largely depends on the community itself. A positive aspect is the fact that self-regulated organizations that unite the subjects of professional activity of a certain type are created at the level of the subjects of the Russian Federation. Even if self-regulated organizations act as a kind of organization for human rights, this will, in our opinion, give positive results. Medical providers will receive another additional lever to defend their professional interests. 
It should be emphasized that the legislative framework has the greatest impact on the development of Russian medical associations. Currently, the legislation describes only general provisions for the activities of medical associations, while other sectors have created special laws regulating the activities of professional communities in a certain area. In the future, it is possible to regulate more strictly the activities of medical associations, which will determine the specific functionality and specificity of such organizations.

The fact that the qualification of doctors who are able to independently regulate and manage their medical activities will always be much higher than the qualification of doctors whose medical activities are controlled and regulated by others is obvious. It is also obvious that a system based on principles of self-organization and self-development, in economic terms, will be much more successful and competitive than one that needs to be to organized and developed from above.

To solve all the above-mentioned issues, it is necessary to improve the regulatory framework, namely the adoption of a federal law determining the status of a doctor as a subject involved in the economic turnover. At the same time, it is possible to form a voluntary self-regulation of the activity of subjects from the professional sphere, which is one of the reasons for the legal basis for ensuring an effective national model of self-regulation formation, defined by the concept of improving the mechanisms of self-regulation, approved by the order of the government of the Russian Federation from 30.12.2015 No. 2776-p. (order of the Russian Federation government from 30.12.2015 No. 2776-p "The concept of self-regulated mechanisms modernization").

\section{References}

Collier, Roger. 2015. "Professionalism: The privilege and burden of self-regulation". Canadian Medical Association Journal 184 (14): 1559-1560.

Goryainov, Aleksei M. 2019. "Professional responsibility of medical workers". Accessed January 27, 2019. http://rosmedconsulting.ru/news24/postid/own_news/94. (In Russian)

Kapranova, Svetlana Y. 2009. "Problems and prospects of development of liability insurance of the medical services in the Russian Federation”. Evraziiskii iuridicheskii zhurnal 11 (18). Accessed January 27, 2019. http://www.eurasialaw.ru/index.php?option=com_jcontentplus\&view=article\&id=4099:2013-04-0306-55-13\&catid=361:2013-04-03-06-51-53\&Itemid=196. (In Russian)

Mikhailov, Leonid A. 2019. "Basis of self-government and self-regulation in professional medical activity." Accessed March 12, 2019. http://svfirstov.ru/ news/Newsline/410.

Natsional'naia meditsinskaia palata. n. d. "The concept of introducing of a self-regulated system of professional activities of medical workers in the Russian Federation". Accessed January 27, 2019. http://www.nacmedpalata.ru/?action=show\&id=17695. (In Russian)

Piven, Dmitrii V., Igor' S. Kitsul. 2011. "Around self-regulation in health". Menedzher zdravookhraneniia 3: 24-30. (In Russian)

Romanovskaya, Ol'ga V. 2016. "Self-regulation in the sphere of private health care system". Publichnopravovye issledovaniia 3: 1-18. (In Russian)

White, William D. 2015. "Professional Self-Regulation in Medicine". American Medical Association Journal of Ethics 16 (4): 275-278.

Zgonnikov, Andrei P., Alla N.Pushkareva 2015. "Professional liability of medical workers' insurance and the problems of medical secrecy confidentiality in the Russian Federation: theoretical aspect". Zakonodatel'stvo i ekonomika 9: 15-19. (In Russian)

Zueva, Elena L., Sviatoslav Yu. Khovaev. 2014. "Self-Regulated Medical Associations in Russia: history, analysis and prospects". Ars administrandi 2: 79-92. 
Authors' information:

Stepan V.Firstov - Board Member; docsf@mail.ru

Tatyana A.Seryak - master student; tanjatselischeva107@gmail.com

Elvira A. Tselishcheva - Independent Board Member; 302165@mail.ru

Olga V.Dobrokhotova — Independent Board Member; dobrohotovaov@mail.ru 